\title{
Alterações morfofisiológicas em folhas de Coffea arabica L. cv. “Oeiras” sob influência do sombreamento por Acacia mangium Willd
}

\author{
Morphophysiological alterations in leaves of Coffea arabica L. cv. 'Oeiras' shaded by \\ Acacia mangium Willd \\ Inês Angélica Cordeiro Gomes ${ }^{\mathrm{I}}$ Evaristo Mauro de Castro ${ }^{\mathrm{II}, *}$ Angela Maria Soares ${ }^{\mathrm{II}}$ \\ José Donizeti Alves ${ }^{\text {II }}$ Maria Inês Nogueira Alvarenga ${ }^{I I I}$ Eduardo Alves ${ }^{\text {IV }}$ \\ João Paulo Rodrigues Alves Delfino Barbosa' ${ }^{\text {II }}$ Daniela Deitos Fries ${ }^{\text {II }}$
}

RESUMO

Diferenças na disponibilidade de radiação podem causar modificações na estrutura e função das folhas do cafeeiro, que podem responder de maneira diferencial à radiação por alterações morfológicas, anatômicas, de crescimento e na taxa fotossintética. O objetivo deste trabalho foi avaliar características morfofisiológicas de cafeeiros (Coffea arabica L. cv. "Oeiras”) sombreados por acácia (Acacia mangium Willd.) na época seca e chuvosa no sul de Minas Gerais. As maiores taxas fotossintéticas e maiores espessuras da epiderme adaxial foram observadas na estação chuvosa nas linhas de cafeeiros a pleno sol. O sombreamento influenciou em menor espessura das folhas e em espaços intercelulares maiores no tecido esponjoso. Foi também verificada mudança na forma dos cloroplastos, os quais apresentaram-se mais alongados em folhas de cafeeiros a pleno sol quando relacionados aos arborizados.

Palavras-chave: cafeeiro, acácia, taxa fotossintética, anatomia foliar, cloroplastos.

\section{ABSTRACT}

Light availability is one of the most important environmental factors affecting leaf structure and functions in coffee plants that can respond differently to radiation by changes in leaf anatomy, morphology, growth and photosynthetic rate. The objective of this research was evaluate some morphophysiological aspects in leaves of coffee (Coffea arabica L. CV. 'Oeiras') cropped under shelter trees in the south of Minas Gerais during the rainy and dry season. The shade caused lower leaves thickness and higher intercellular spaces in spongious tissue. There was also verified a change in chloroplast shape, which showed more elongated in coffee tree kept at full sunlight in relation to that ones maintained on shading.

Key words: coffee, acacia, shade, photosynthetic rate, leaf structure, chloroplast.

\section{INTRODUÇÃO}

Uma variedade de fatores ambientais, especialmente a disponibilidade de radiação, pode causar alterações nas características estruturais e funcionais das folhas, culminando com alterações no padrão de crescimento e produção das plantas (BJÖRKMAN, 1981). Plantas que apresentam plasticidade morfofisiológica, ou seja, capacidade de aclimatação a diferentes condições de ambiente, são capazes de responder diferencialmente a níveis de radiação no ambiente por alterações anatômicas, morfológicas e fotossintéticas (PANDEY \& KUSHWAHA, 2005; OGUCHI et al., 2005).

De maneira geral, plantas que possuem plasticidade apresentam aumento nos teores de clorofila, queda na atividade da RUBISCO (ribulose1,5-bisfosfato carboxilase/oxigenase), redução na taxa fotossintética líquida e incremento na área foliar específica quando em ambientes com baixa disponibilidade de radiação (NIINEMETS et al., 1998; MORAIS et al., 2004).

\footnotetext{
IDepartamento de Biologia, Universidade Federal de Pelotas (UFPel), Pelotas, RS, Brasil.

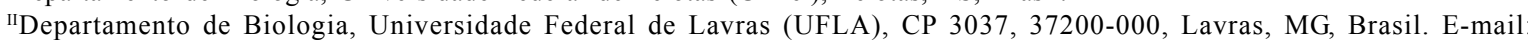
emcastro@ufla.br.*Autor para correspondência.

IIIEmpresa de Pesquisa Agropecuária de Minas Gerais (EPAMIG), Lavras, MG, Brasil.

${ }^{\mathrm{IV}}$ Departamento de Fitopatologia, UFLA, Lavras, MG, Brasil.
} 
A espécie Coffea arabica L. é originária das florestas da Etiópia, onde pode ser encontrada sob a proteção das árvores. Entretanto, as cultivares mais difundidas atualmente foram melhoradas geneticamente para apresentar alta produção em condições de pleno sol, o que pode ter causado a perda da capacidade de adaptar-se a diferentes ambientes (CAMPANHA et al., 2004). Contudo, VOLTAN et al. (1992) e MORAIS et al. (2004), trabalhando com cultivares melhoradas para pleno sol, observaram que Coffea arabica L. apresenta uma elevada plasticidade fenotípica, podendo se adaptar a várias condições de disponibilidade de radiação, o que permite o seu cultivo em sistemas agroflorestais com resultados satisfatórios.

No entanto, em cultivos de cafeeiros sombreados, observa-se que as plantas devem adaptarse à baixa disponibilidade de radiação e, por isso, em geral, apresentam uma diminuição na produtividade de pelo menos $20 \%$ em relação a cafeeiros a pleno sol (FOURNIER, 1988; DA MATTA \& RENA, 2002; MORAIS et al., 2003; DA MATTA, 2004). Porém, alguns autores apontam que cafeeiros sob sombra apresentam maiores taxas fotossintéticas, maior crescimento, maior resistência à seca e produções mais constantes ao longo dos anos, uma vez que a redução da radiação pelas árvores e a manutenção do microclima ao longo do ano pode evitar danos por fotoinibição e fotooxidação, reduzindo o efeito da bianualidade sobre a produção (BEER et al., 1997; FAHL et al., 1989; FREITAS et al., 2003; CAMPANHA et al., 2004).

Com base na hipótese de que a arborização, além do efeito direto na redução da radiação, também altera o microclima e o balanço hídrico da lavoura como efeitos indiretos da disponibilidade de água no solo e na atmosfera, MORAIS et al. (2004) relatam que pode ocorrer modificação estrutural e funcional em resposta às condições hídricas, imprimindo às folhas de sol alguns caracteres xeromórficos, como parênquima paliçádico mais diferenciado e mais espesso em relação às folhas de sombra.

São numerosos os trabalhos voltados para aspectos agronômicos de cafeeiros sombreados por leguminosas arbóreas, assim como existem muitos estudos anatômicos do cafeeiro em condição de sombreamento artificial em fase jovem. Contudo, poucos estudos anatômicos abordam cafeeiros em sistemas sombreados naturalmente, em condições de campo. Nesse contexto, o objetivo deste trabalho foi avaliar modificações nas características morfofisiológicas de folhas de cafeeiros (Coffea arabica L. cv. "Oeiras") sombreados por acácia (Acacia mangium Willd.) durante a época seca e a chuvosa no sul de Minas Gerais.

\section{MATERIAL E MÉTODOS}

O estudo foi realizado na fazenda experimental da Empresa de Pesquisa Agropecuária de Minas Gerais (EPAMIG), em São Sebastião do Paraíso, na região sul do Estado de Minas Gerais, latitude 2054'48'S e longitude 46 59'36'W. A altitude média é de $1.040 \mathrm{~m}$, com temperatura média anual de $21,0^{\circ} \mathrm{C}$ e precipitação anual de $1.387 \mathrm{~mm}$, apresentando inverno seco e frio e verão quente e chuvoso.

As avaliações foram realizadas em folhas de cafeeiros (Coffea arabica L. cv. “Oeiras”), plantados em 1999 juntamente com uma aléia de acácia (Acacia mangium Willd.). A aléia é composta de três linhas espaçadas de $1,5 \mathrm{~m}$ e com $3,0 \mathrm{~m}$ entre plantas. As plantas da linha central são intercaladas com as plantas das linhas das extremidades. Os cafeeiros foram plantados em linhas paralelas à faixa de acácia, no espaçamento de $3,5 \mathrm{~m}$ x $0,5 \mathrm{~m}$. Foram estudadas plantas situadas na primeira linha à oeste da aléia de acácia, que estão sujeitas a um maior período de sombreamento ao longo do dia devido à orientação do plantio (norte - sul), e também cafeeiros situados em linhas que não estavam sob influência do sombreamento (pleno sol).

Foram realizadas avaliações de trocas gasosas com um analisador portátil de $\mathrm{CO}_{2}$ a infravermelho (IRGALCA-4 ADC Hoddesdon, UK), em dias típicos, predominantemente claros, entre as $10 \mathrm{e}$ 11 horas, nas estações chuvosa e seca (março e julho de 2003, respectivamente), em folhas completamente expandidas do terceiro nó de ramos do terço superior das plantas de café. Utilizou-se uma folha de cada planta e quatro plantas por tratamento. A umidade relativa e a temperatura da cubeta foram utilizadas para determinar os valores do déficit de pressão de vapor na atmosfera (DPV) no momento da avaliação.

As folhas utilizadas nas avaliações morfoanatômicas foram coletadas no mesmo par de folhas utilizadas para as avaliações de trocas gasosas e conservadas em etanol $70^{\circ} \mathrm{GL}$. Para a confecção das lâminas, seções de $0,5 \mathrm{~cm}^{2}$ foram feitas à mão livre no terço médio foliar. As seções foram clarificadas em solução $50 \%$ de hipoclorito de sódio, sendo, em seguida, lavadas em água destilada, neutralizadas em água acética $1 \%$, coradas com azul de astra e safranina e montadas em glicerina 50\% (KRAUS \& ARDUIN, 1997). As medições das espessuras das epidermes abaxial e adaxial, parênquima paliçádico e esponjoso e a espessura do limbo foliar foram feitas em três regiões distintas de cada seção, utilizando-se uma ocular micrometrada, perfazendo um total de 15 medições para cada tratamento.

Ciência Rural, v.38, n.1, jan-fev, 2008. 
Foram também coletadas cinco folhas de cada tratamento, nas mesmas condições utilizadas para as avaliações de trocas gasosas, de onde foram retirados fragmentos de $0,5 \mathrm{~cm}^{2}$, aproximadamente, os quais foram imersos em solução fixadora $[2,5 \%$ glutaraldeído e 2,5\% paraformaldeído em tampão cacodilato $0,05 \mathrm{M}(\mathrm{pH} 7,0)+\mathrm{CaCl}_{2} 0,001 \mathrm{M}$ por, pelo menos, uma hora, sob temperatura ambiente], lavados em tampão cacodilato $0,05 \mathrm{M}$ (três vezes de 10 minutos) e pós-fixados em tetróxido de ósmio $1 \%$ em tampão cacodilato $0,05 \mathrm{M}$ por $1-2$ horas. Em seguida, iniciou-se a desidratação em gradiente de acetona $(30,50,70,90$ por 10 minutos e três vezes de 10 minutos em $100 \%$ ). Logo após, o material foi incluído em gradiente crescente de acetona e resina Spurr $30 \%$ por 8 horas, $70 \%$ por 12 horas e $100 \%$, duas vezes por 24 horas cada, e polimerizado em estufa a $70^{\circ} \mathrm{C}$, por 48 horas, em forma de silicone. Os blocos obtidos foram desbastados com lâminas de barbear para a retirada dos excessos. Em seguida, foram obtidas seções semifinas $(0,85 \mu \mathrm{m}) \mathrm{e}$ ultrafinas $(<100 \mathrm{~nm})$ usando-se um ultramicrotomo Reichrt-jung (ultracut), com o auxílio de navalha de diamante. Os cortes semifinos foram coletados com anel de ouro, colocados em lâminas de vidro, coloridos com azul de toluidina ( $1 \mathrm{~g}$ de azul de toluidina, $1 \mathrm{~g}$ de borato de sódio e $100 \mathrm{~mL}$ de água filtrados em filtro Millipore $0,2 \mu \mathrm{m}$ ) e montados permanentemente em meio Permalt. Os cortes ultrafinos foram coletados em grades de cobre e pós-contrastados em acetato de uranila, seguido por acetato de chumbo por três minutos cada, e, em seguida, examinados em microscópio eletrônico de transmissão Zeiss EM 109 a 80kv.

O delineamento experimental utilizado foi em blocos ao acaso, sendo a unidade experimental composta por duas plantas. Foram feitas análises de variância, e as médias comparadas pelo teste de ScottKnott a 5\% de probabilidade.

\section{RESULTADOS E DISCUSSÃO}

A acácia promoveu uma alteração significativa na quantidade de radiação que atinge o topo dos cafeeiros. Isso pode ser observado através das condições de DFFFA (Densidade de Fluxo de Fótons Fotossinteticamente Ativos) e DPV (Déficit de Pressão de Vapor) correspondentes às avaliações de trocas gasosas, como mostra a figura 1A. Os cafeeiros sombreados apresentaram menores valores de DFFFA em relação às plantas cultivadas a pleno sol em ambas as estações. Em relação ao DPV, observou-se, na época seca menores valores para o cultivo sombreado. $\mathrm{Na}$ época chuvosa, não houve diferença de DPV entre os sistemas de cultivo, possivelmente pela maior umidade relativa do ar nessa época.

$\mathrm{Na}$ linha de cafeeiros arborizada, não houve diferença significativa entre as épocas quanto ao DPV.

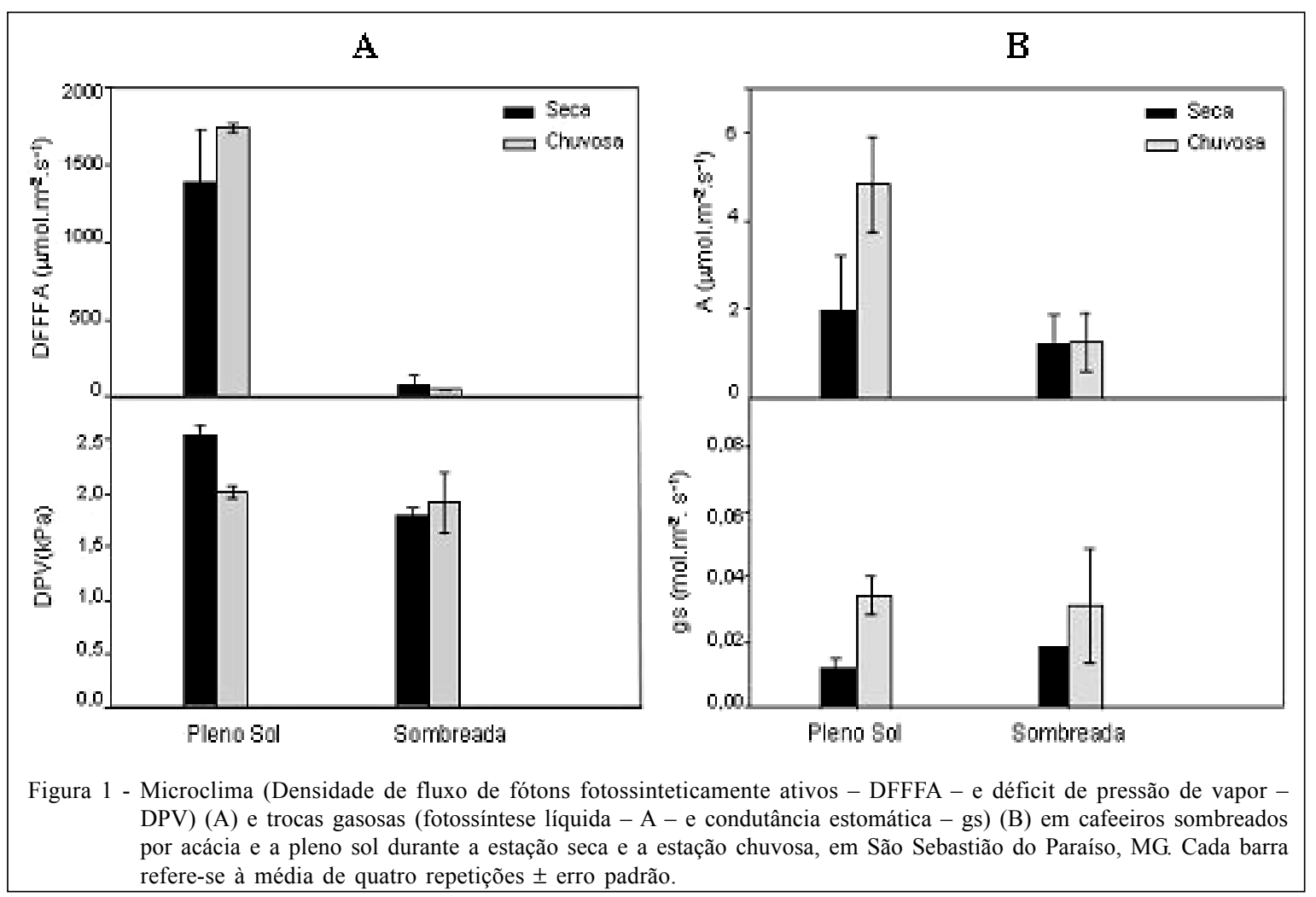

Ciência Rural, v.38, n.1, jan-fev, 2008. 
Contudo, para os cafeeiros a pleno sol, verificou-se maiores valores de DPV na época seca em relação à chuvosa (Figura 1A). A manutenção de valores de DPV, ao longo do ano, em cultivo de cafeeiros sombreados, também foi observada por vários autores citados por BEER et al. (1997). Nesses trabalhos e em estudo realizado por CAMPANHA et al. (2004), a manutenção do microclima é apontada como uma das principais vantagens da arborização da lavoura de café, pois o abrigo das árvores evita altos valores de DPV, extremos de temperatura e excesso de radiação, que podem causar fotoinibição e fotooxidação.

Observou-se que uma condição de maior DFFFA associada a um menor DPV (estação chuvosa) favoreceu o processo fotossintético nas plantas de café a pleno sol (Figura 1B). Este resultado concorda com os resultados de diferentes estudos, entre eles MORAIS et al. (2003) e DA MATA (2004), nos quais maiores valores de fotossíntese foram verificados para cultivos a pleno sol. De fato, o processo de seleção das variedades atuais levou à escolha de plantas adaptadas a condições de elevada disponibilidade de radiação. Essa seleção pode ter causado erosão genética em relação a sua condição original de planta de sub-bosque, como relatado por CAMPANHA et al. (2004), o que pode desfavorecer a sua taxa fotossintética em condições de baixa disponibilidade de radiação, pela perda de plasticidade. Nesse caso, a fotossíntese seria limitada pela escassez de energia radiativa e não por fatores estruturais ou funcionais.

Os cafeeiros a pleno sol apresentaram maior espessura do limbo foliar em relação aos cafeeiros sombreados, especialmente na época chuvosa (Tabela 1). Esse aumento na espessura do limbo causa redução da área foliar específica, o que, segundo alguns autores, confere às plantas a pleno sol uma maior capacidade fotossintética por unidade de área foliar em comparação com folhas de sombra (NIINEMETS et al., 1998; LIAO et al, 2005; OGUCHI et al., 2005; PANDEY \& KUSHWAHA, 2005).

Entre as estações, para os cafeeiros a pleno sol, constatou-se uma redução significativa da taxa fotossintética na estação seca, indicando que a baixa disponibilidade de água no solo, associada a uma maior demanda evaporativa da atmosfera, limita a fotossíntese do cafeeiro quando há elevada disponibilidade de radiação, principalmente devido ao fechamento estomático, como pode ser verificado na figura $1 \mathrm{~B}$. Esses resultados estão de acordo com SILVA et al. (2004), que mostram que a fotossíntese do cafeeiro é amplamente controlada pela abertura estomática. Quando há maior disponibilidade de água (estação chuvosa), a condutância estomática é maior, conseqüentemente, observaram-se maiores valores de taxa fotossintética (Figura 1B).

Em relação às plantas sob influência do sombreamento, observou-se que tanto as taxas fotossintéticas quanto a condutância estomática não diferiram ao longo do ano, entre as estações. Esses resultados indicam que o nível de sombreamento provocado pela acácia permite uma menor variação do ambiente ao longo do ano. Deve-se destacar que a condição de sombreamento contribui para a manutenção de outros fatores ambientais em relação ao pleno sol, como maior disponibilidade de água no solo e temperatura do ar, que são condições características do ambiente sombreado e que poderiam beneficiar as trocas gasosas do cafeeiro (DA MATTA, 2004).

Uma vez que o microclima do cafeeiro sombreado por acácia pode se considerado como mais propício à fotossíntese, os menores valores de

Tabela 1 - Espessura $(\mu \mathrm{m})$ do tecido epidérmico (adaxial e abaxial), dos parênquimas paliçádico e esponjoso e do limbo foliar de folhas de cafeeiros sombreados por acácia e a pleno sol, na estação chuvosa e na estação seca.

\begin{tabular}{|c|c|c|c|c|c|}
\hline & \multirow{2}{*}{ Espessura $(\mu \mathrm{m})$} & & \multirow{2}{*}{ Estação } & \multicolumn{2}{|c|}{ Linha } \\
\hline & & & & Pleno Sol & Sombreada \\
\hline \multirow{4}{*}{ Epiderme } & \multirow{2}{*}{\multicolumn{2}{|c|}{ Face adaxial }} & Seca & $34,14 \mathrm{a}$ & $31,38 \mathrm{~b}$ \\
\hline & & & Chuvosa & $33,48 \mathrm{a}$ & $29,69 \mathrm{~b}$ \\
\hline & \multirow{2}{*}{\multicolumn{2}{|c|}{ Face abaxial }} & Seca & $34,14 \mathrm{a}$ & $31,38 \mathrm{a}$ \\
\hline & & & Chuvosa & $22,81 \mathrm{~b}$ & $18,99 \mathrm{~b}$ \\
\hline \multirow{6}{*}{ Parênquima } & \multirow{2}{*}{\multicolumn{2}{|c|}{ Paliçádico }} & Seca & $72,21 \mathrm{a}$ & $69,84 \mathrm{a}$ \\
\hline & & & Chuvosa & $62,02 \mathrm{a}$ & $55,08 \mathrm{~b}$ \\
\hline & \multirow{2}{*}{\multicolumn{2}{|c|}{ Esponjoso }} & Seca & $193,23 \mathrm{~b}$ & $189,26 \mathrm{~b}$ \\
\hline & & & Chuvosa & $212,12 \mathrm{a}$ & $203,33 \mathrm{~b}$ \\
\hline & \multirow{2}{*}{\multicolumn{2}{|c|}{ Limbo }} & Seca & $333,72 \mathrm{a}$ & $321,86 \mathrm{a}$ \\
\hline & & & Chuvosa & $330,43 \mathrm{a}$ & $307,09 \mathrm{~b}$ \\
\hline
\end{tabular}

*Médias seguidas pelas mesmas letras minúsculas na horizontal não diferem entre si pelo teste de Scott-Knott a 5\% de probabilidade.

Ciência Rural, v.38, n.1, jan-fev, 2008. 
assimilação de carbono observados nas plantas sombreadas parecem estar então relacionados aos baixos níveis de radiação observados no presente estudo para a condição de cultivo sombreado $(5 \%$ da radiação observada na condição de pleno sol). Resultados semelhantes foram verificados no trabalho de FAHL et al. (1994) e CARELLI et al. (1999), nos quais a fotossíntese foi menor em cafeeiros cultivados em condições sombreadas, e essa redução foi associada à limitação da fotossíntese pela escassez de radiação.

Em avaliações da estrutura interna, foi observado que as células em paliçada, tanto de folhas de plantas sombreadas como a pleno sol, apresentaramse bem organizadas, sendo constituídas de apenas uma camada. Porém, ocorreu menor adensamento das células do parênquima paliçádico com o sombreamento das plantas. Tais resultados confirmam dados anteriormente obtidos em cafeeiro por FAHL (1989), que verificou maior espessura e densidade de células em folhas desenvolvidas a pleno sol. Os valores da espessura dos parênquimas paliçádico e esponjoso diferiram entre si na estação chuvosa, sendo os maiores valores encontrados no tratamento a pleno sol. A espessura do limbo foliar apresentou diferença significativa entre os tratamentos também na estação chuvosa (Tabela 1).

As alterações observadas entre folhas de cafeeiros expostas a diferentes níveis de radiação podem ser atribuídas a diferentes concentrações de fitohormônios, especialmente da auxina (MORAIS et al., 2004). Dentre suas funções, as auxinas exercem a promoção do crescimento e da distensão celular, e como uma das suas característica é a fotosensibilidade, as moléculas de auxina se concentram nas regiões menos iluminadas da folha. Como há maior concentração em regiões sombreadas, as folhas mais iluminadas apresentam maiores teores desse fitohormônio no mesofilo, enquanto que, em folhas sombreadas, as auxinas são encontradas em toda a folha, inclusive na epiderme (MEDRI \& LLERAS, 1980). Esta distribuição diferencial de auxinas pode ser uma das causas prováveis, em grande parte, pelas diferenças estruturais observadas entre folhas de cafeeiros de sol e sombra, permitindo a maior distensão de células da epiderme em folhas de plantas sombreadas.

Independentemente do tratamento, os cafeeiros estudados apresentaram mesofilo dorsiventral. O parênquima paliçádico apresentou-se denso e composto por células alongadas, dispostas perpendicularmente à superfície adaxial da folha. $\mathrm{O}$ parênquima esponjoso apresentou-se com grandes espaços intracelulares e com continuidade predominantemente horizontal, paralela à superfície da folha.
Os resultados mostram que as estações do ano tiveram efeito significativo sobre a espessura do limbo foliar dos cafeeiros sombreados por acácia (Tabela 1). Observações das seções transversais das lâminas foliares mostraram maior espessura do limbo nos cafeeiros cultivados a pleno sol; porém, as estações do ano não tiveram efeito significativo sobre tal característica. O decréscimo na espessura foliar dos cafeeiros sombreados por acácia provavelmente ocorreu em decorrência da diferença na distribuição de fotoassimilados, em relação às plantas cultivadas a pleno sol, que tiveram folhas mais espessas. Esses resultados corroboram os de VOLTAN et al. (1992) e MORAIS et al. (2004), que verificaram que as folhas de cafeeiro expostas a maiores níveis de radiação apresentaram maior espessura do limbo. Maior espessura dos tecidos do mesofilo em folhas a pleno sol também foram observados em outras espécies, como Cupania vernalis Camb., que, cultivadas a pleno sol, apresentaram maiores espessuras do limbo em relação às cultivadas sob sombreamento (LIMA Jr et al., 2005).

$\mathrm{O}$ aumento em espessura das células do parênquima paliçádico é resultante de um alongamento deste tecido no sentido abaxial, o que pode ser indiferente em relação à área do limbo em relação a espessura da folha. No entanto, isso aumenta significativamente o volume do mesofilo por área foliar, o que pode ser importante para a as trocas gasosas em condições de elevada irradiância ou restrição hídrica (BJÖRKMAN, 1981; VOLTAN et al., 1992).

Além disso, pode ser verificada uma abundância de espaços intracelulares no mesofilo das folhas de plantas arborizadas em relação às cultivadas a pleno sol, principalmente no parênquima esponjoso. De acordo com os resultados obtidos por MORAIS et al. (2004), cafeeiros cultivados a pleno sol apresentaram menores espaços intracelulares. Segundo os autores, este seria um mecanismo de resistência mecânica da folha, representado por um grande desenvolvimento do mesofilo. Ademais, essa é uma característica xerofítica comum, já que pode ser interpretada como uma característica estrutural capaz de reduzir efeitos prejudiciais em caso de murchamento produzido por déficit hídrico. Além disso, a presença de tais espaços contribui para que uma maior quantidade de radiação atinja os cloroplastos devido a uma menor atenuação da radiação pelas células do mesofilo.

A morfologia e o tamanho dos cloroplastos (Figura 2), bem como a parede celular do parênquima paliçádico das folhas, alterou-se de acordo à condição de luminosidade. Verifica-se que os cloroplastos dos cafeeiros a pleno sol apresentaram um aumento de tamanho em relação aos cafeeiros sombreados, visando 

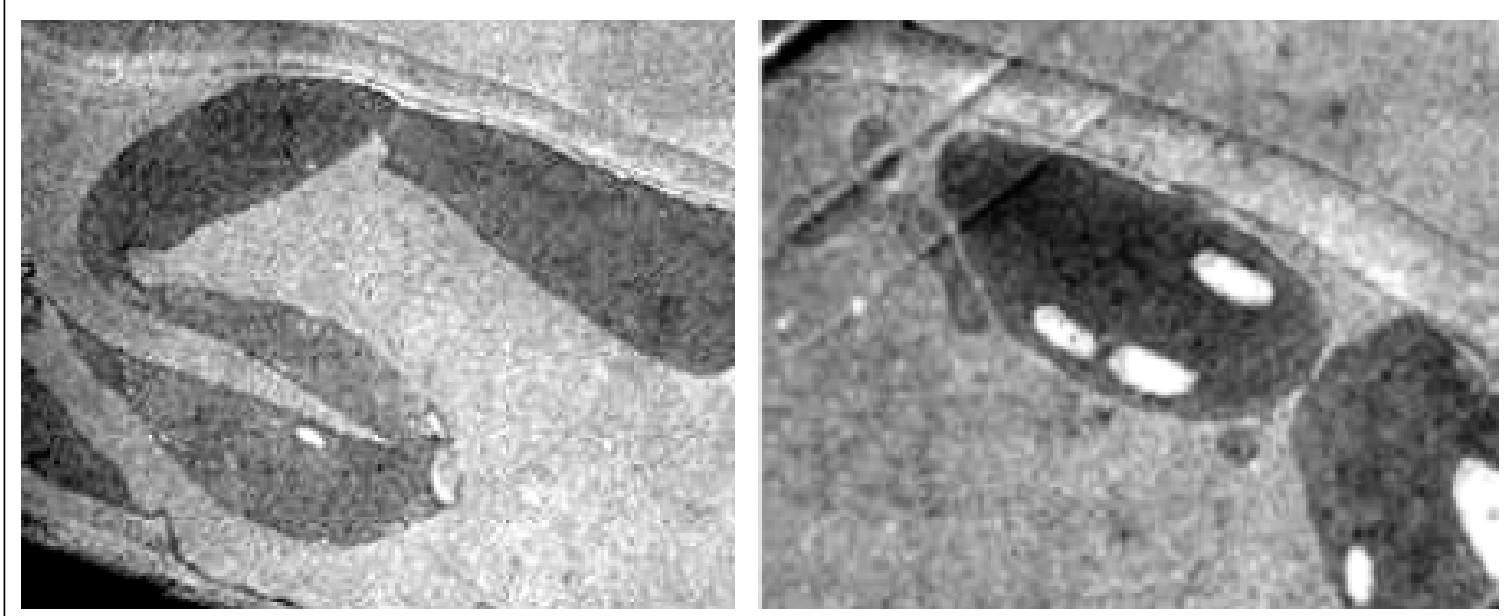

Figura 2 - Eletromicrografia de transmissão (MET) de cloroplastos de folhas de cafeeiros sombreados por acácia e de cafeeiros a pleno sol. A- cloroplastos da linha a pleno sol, 3000x; B- cloroplastos da linha sombreada, 4400x.

promover maior captação da luz para a fotossíntese, uma vez que os cafeeiros nessa condição apresentaram as menores taxas para essa característica em ambas as estações.

\section{CONCLUSÃO}

O sombreamento e as modificações sazonais (épocas chuvosa e seca) às quais as plantas foram submetidas promoveram efeitos diversos sobre características fisiológicas e anatômicas, apresentando melhor desempenho fotossintético nas linhas de cafeeiros a pleno sol e na época chuvosa.

As adaptações morfológicas ocorreram, principalmente, na espessura das folhas (que diminuiu com o sombreamento) e no tecido esponjoso, que apresentou espaços intercelulares maiores nas folhas sob o sombreamento causado pela acácia. A forma dos cloroplastos também foi alterada, tornando-se mais alongada nas plantas a pleno sol.

\section{REFERÊNCIAS}

BEER, J. et al. Shade manegement in coffe and cação plantations. Agroforetry Systems, Baltimore, v.38, n.1-3, p.139-164, 1997.

BJÖRKMAN, O. Responses to different quantum flux densities. In: LANGE, O.L. et al. Encyclopedia of plant physiology. Berlin: Springer-Verlag, New Series, 1981. V.12A, p.57-107.

CAMPANHA, M.M. et al. Growth and yield of coffee plants in agroforestry and monoculture systems in Minas Gerais, Brazil. Agroforetry Systems, Baltimore, v.63, n.1, p.75-82, 2004.

CARELLI, M.L.C. et al. Carbon isotope discrimination and gas exchange in Coffea species grown under different irradiance regimes. Revista Brasileira de Fisiologia Vegetal, Brasília, v.11, n.2, p.63-68, 1999.
DA MATTA, F.M.; RENA, A.B. Ecofisiologia de cafezais sombreados e a pleno sol. In: ZAMBOLIM, L. (Ed.). O estado da arte de tecnologias na produção de café. Viçosa: UFV, 2002. p.93-136.

DA MATTA, F.M. Ecophysiological constrains on the production of shaded and unshaded coffee: a review. Field Crops Research, Phoenix, v.86, n.2-3, p.99-114, 2004.

FAHL, J.I. et al. Nitrogen and irradiance levels affecting net photosynthesis and growth of young coffee plants (Coffea arabica L. cv. Oeiras). Journal of Horticultural Science, Ashford, v.69, n.1, p.161-169, 1994.

FAHL, J.I. Influência da irradiância e do nitrogênio na fotossíntese e crescimento de plantas jovens de café (Coffea arabica L.). 1989. 84f. Tese (Doutorado em Ciências Biológicas) - Universidade Estadual de Campinas.

FOURNIER, L.A. El cultivo del cafeto (Coffea arabica L.) al sol o a la sombra: um enfoque agronômico y ecofisiologico. Agronomía Costarricense, Costa Rica, v.12, n.1, p.131146, 1988.

FREITAS, R.B. DE et al. Influência de diferentes níveis de sombreamento no comportamento fisiológico de cultivares de café (Coffea arabica L.). Ciência e Agrotecnologia, Lavras, v.27, n.4, p.804-810, 2003.

KRAUS, J.E.; ARDUIN, M. Manual básico de métodos em morfologia vegetal. Rio de Janeiro: Seropédica, 1997. 198p.

LIAO, J.X. et al. Effects of irradiance on photosynthetic characteristics and growth of Mosla chinensis and M. scabra. Photosynthetica, Praga, v.43, n.1, p.111-115, 2005.

LIMA JÚNIOR, E. DE C. et al. Trocas gasosas, características das folhas e crescimento de plantas jovens de Cupania vernalis Camb. submetidas a diferentes níveis de sombreamento. Ciência Rural, Santa Maria, v.35, n.5, p.1092-1097, 2005. 
MEDRI, M.E.; LLERAS, E. Aspectos da anatomia de folhas de Hevea brasiliensis Muell. Arg. Acta Amazônica, Manaus, v.10, n.3, p.463-493, 1980 .

MORAIS, H. et al. Características fisiológicas e de crescimento de cafeeiros sombreados com guandu e cultivados a pleno sol. Pesquisa Agropecuária Brasileira, Brasília, v.38, n.10, p.1131-1137, 2003.

MORAIS, H. et al. Modifications on leaf anatomy of Coffea arabica caused by shade of Pigeonpea (Cajanus cajan) Brazilian Archives of Biology and Technology, Curitiba, v.47, n.6, p.863-871, 2004.

NIINEMETS, U. et al. An analysis of light effects on foliar morphology, physiology, and light interception in temperate deciduous woody species of contrasting shade tolerance. Tree Physiology, Canadá, v.18, n.10, p.681-696, 1998.
OGUCHI, R. et al. Leaf anatomy as a constraint for photosynthetic acclimation: differential responses in leaf anatomy to increasing growth irradiance among three deciduous trees. Plant, Cell and Environment, Oxford, v.28, n.7, p.916-927, 2005.

PANDEY, S.; KUSHWAHA, R. Leaf anatomy and photosynthetic acclimation in Valeriana jatamansi L. grown under high and low irradiance. Photosynthetica, Praga, v.43, n.1, p.85-90, 2005 .

SILVA, E.A. et al. Seasonal changes in vegetative growth and photosynthesis of Arábica cofee trees. Fields Crops Research, Phoenix, v.89, n.2-3, p.349-357, 2004.

VOLTAN, R.B.Q. et al. Variação na anatomia foliar de cafeeiros submetidos a diferentes intensidades luminosas. Revista Brasileira de Fisiologia Vegetal, Londrina, v.4, n.2, p.99105, 1992. 